\title{
Stationary phase expression of the arginine biosynthetic operon argCBH in Escherichia coli
} Jeevaka P Weerasinghe ${ }^{\dagger}$, Tao Dong ${ }^{\dagger}$, Michael R Schertzberg, Mark G Kirchhof, Yuan Sun and Herb E Schellhorn*

Address: McMaster University, Department of Biology, Life Sciences Building, Rm. 218, 1280 Main Street West, Hamilton, ON, Canada, L8S 4K1

Email: Jeevaka P Weerasinghe - jeevakapramukw@hotmail.com; Tao Dong - dongt2@mcmaster.ca;

Michael R Schertzberg - mschertzberg@yahoo.ca; Mark G Kirchhof - mkirchhof@robarts.ca; Yuan Sun - ysunny999@yahoo.ca;

Herb E Schellhorn* - schell@mcmaster.ca

* Corresponding author †Equal contributors

Published: 22 February 2006

BMC Microbiology2006, 6:14 doi:|0.1/86/147|-2|80-6-14
Received: 25 August 2005

Accepted: 22 February 2006

This article is available from: http://www.biomedcentral.com/l47I-2/80/6/14

(c) 2006Weerasinghe et al; licensee BioMed Central Ltd.

This is an Open Access article distributed under the terms of the Creative Commons Attribution License (http://creativecommons.org/licenses/by/2.0), which permits unrestricted use, distribution, and reproduction in any medium, provided the original work is properly cited.

\begin{abstract}
Background: Arginine biosynthesis in Escherichia coli is elevated in response to nutrient limitation, stress or arginine restriction. Though control of the pathway in response to arginine limitation is largely modulated by the ArgR repressor, other factors may be involved in increased stationary phase and stress expression.
\end{abstract}

Results: In this study, we report that expression of the $\operatorname{argCBH}$ operon is induced in stationary phase cultures and is reduced in strains possessing a mutation in rpoS, which encodes an alternative sigma factor. Using strains carrying defined $\arg R$, and rpoS mutations, we evaluated the relative contributions of these two regulators to the expression of $\operatorname{argH}$ using operon-lac $\mathrm{Z}$ fusions. While ArgR was the main factor responsible for modulating expression of $\arg C B H, R p o S$ was also required for full expression of this biosynthetic operon at low arginine concentrations (below $60 \mu \mathrm{M} \mathrm{L-}$ arginine), a level at which growth of an arginine auxotroph was limited by arginine. When the $\arg \mathrm{CBH}$ operon was fully de-repressed (arginine limited), levels of expression were only one third of those observed in $\triangle \operatorname{argR}$ mutants, indicating that the $\operatorname{argCBH}$ operon is partially repressed by ArgR even in the absence of arginine. In addition, $\operatorname{argCBH}$ expression was 30-fold higher in $\triangle \operatorname{argR}$ mutants relative to levels found in wild type, fully-repressed strains, and this expression was independent of RpoS.

Conclusion: The results of this study indicate that both derepression and positive control by RpoS are required for full control of arginine biosynthesis in stationary phase cultures of $E$. coli.

\section{Background}

The biosynthesis and/or scavenging of arginine are important during host colonization by uropathogenic Escherichia coli. In urine, expression of the E. coli argCBH operon and artJ, encoding a periplasmic transporter, increases more than 10 fold [1] and 18 fold [2], respec- tively. Synthesis of arginine is likely required during infection as the concentration of arginine found in urine is below that necessary to support maximal growth of $E$. coli [1]. Consistent with these data, infection challenge in a murine model with $E$. coli strains carrying mutations in the $\arg C$ gene results in impaired proliferation in the kid- 
ney [1]. In enteropathogenic E. coli [3] arginine synthesis and transport, together with arginine decarboxylase (encoded by adiA), are important components of the cell's acid resistance repertoire [3-5].

Under nutrient-limiting conditions, E. coli can potentially utilize arginine as both a carbon and a nitrogen source [6]. Arginine is a precursor for the synthesis of polyamines, putrescine and spermidine, which may reduce oxidative damage to proteins and DNA $[7,9]$. In addition, in phosphate-starved cells, aerobic metabolism of arginine may be an important physiological adaptation that is intimately associated with cell survival [10]. Since arginine contains $11 \%$ of the cell's nitrogen in stationary phase [11], biosynthesis of this amino acid is likely important under sub-optimal conditions.

Arginine is synthesized by a complex biosynthetic pathway consisting of several operons and unlinked genes that are controlled by ArgR [12] which represses by binding to a conserved ARG box $[13,14]$ to overlap with RNA polymerase binding sites. Maximum derepression occurs in the absence of arginine [12]. In contrast to most amino acid biosynthetic genes, the expression of the arg biosynthetic genes increases briefly during diauxic growth arrest [15]. As this stress is similar to that imposed by nutrient limitation, it is plausible that stationary phase regulators participate in control of arginine biosynthesis. Several enzymes required for arginine catabolism are controlled by RpoS, an alternative stationary phase sigma factor [16], including those encoded by ast $D[11,17]$, and $\operatorname{cst} C$ (astC) $[11,18]$. Many of the members of the large RpoS regulon are specifically expressed during the transition to stationary phase growth $[19,20]$. Although clearly required for virulence in Salmonella [21], the role of RpoS in the pathogenesis of $E$. coli is equivocal. RpoS controls many functions that contribute to host adaptation, including osmotic stress [22] and acid challenge [3]. In E. coli, however, RpoS mutants are not impaired in colonization of the urinary tract [23] or gastrointestinal tract [24] in ani-
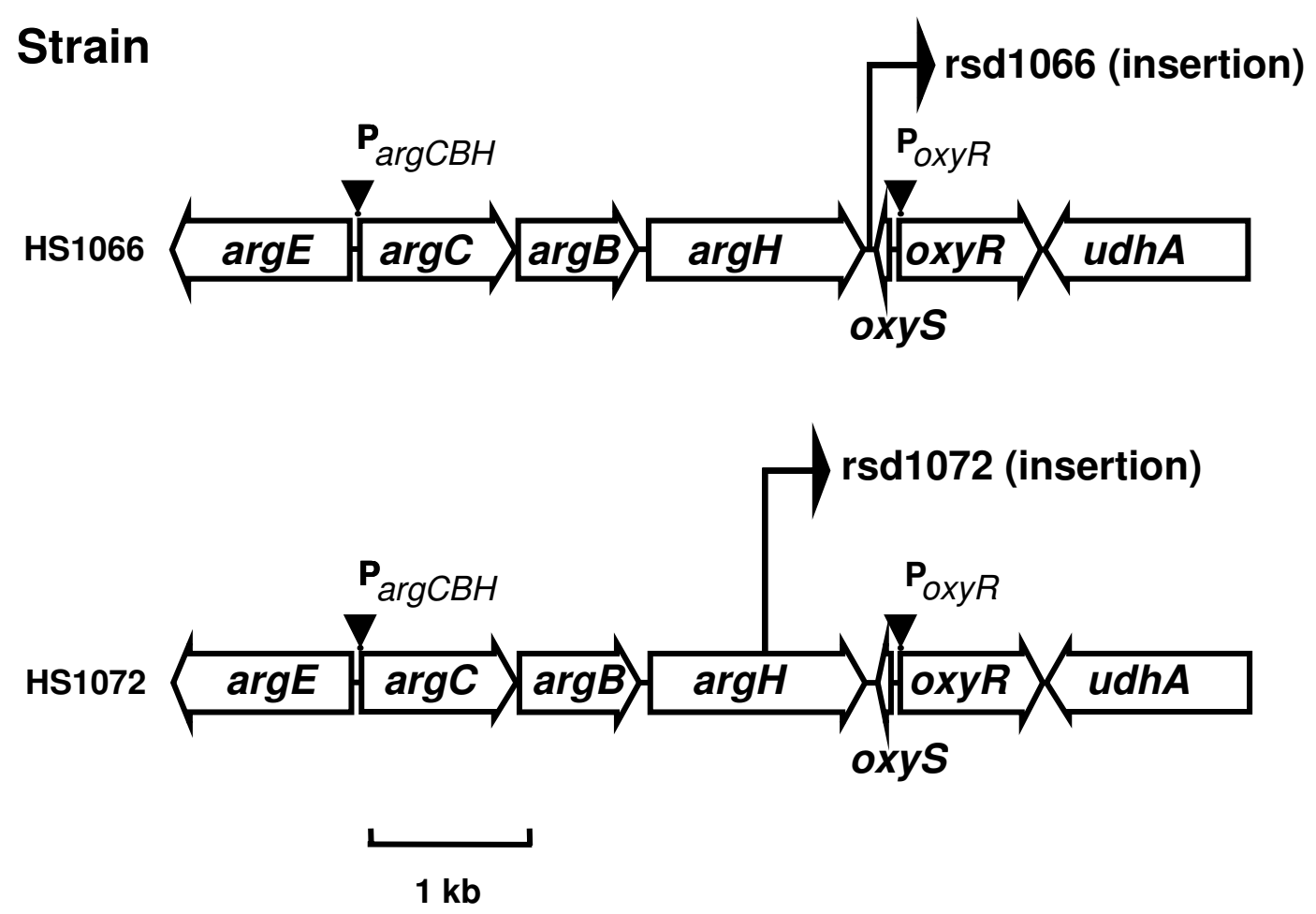

Figure I

Location of operon fusions in strains used in this study. Arrows indicate the direction of transcription of genes. 


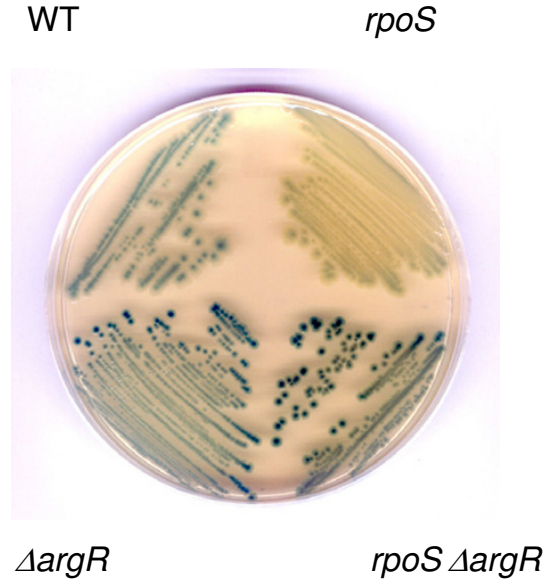

\section{Figure 2}

Expression of $\operatorname{argCBH}$-lacZ in WT, $\Delta r p o S, \Delta \arg R$ and $\Delta r p o S-$ $\triangle \arg R$ strains on LB plates containing $X-G a l$.

mal models. There are several different alleles of RpoS found in natural populations of E. coli [25], and it is thus possible that RpoS regulation may be strain specific.

In a previous study, we identified many independent RpoS-dependent operon fusions [26]. Two of these mapped to the $\operatorname{argCBH}$ operon and were of particular interest because, unlike other RpoS-regulated functions that we identified, this operon, when mutated, rendered the cell auxotrophic. In this study, we have employed these fusions as probes to examine regulatory controls on transcription of the $\arg C B H$ operon to identify how this key biosynthetic pathway is activated.

\section{Results \\ Characterization of argCBH operon fusions}

In a large mutational screen, we isolated over 100 RpoS dependent operon-lacZ fusions [26,27], many of which were not known to require RpoS for expression. Two of the isolated fusion mutations mapped to the $\operatorname{argCBH}$ operon (Fig. 1) and were clearly RpoS-dependent on indicator plates (Fig. 2). While both fusions were in $\operatorname{argH}$; one was intragenic and, as expected, rendered the cell auxotrophic for arginine (rsd1072) and the other fusion ( $r s d 1066)$ was located between the $\operatorname{argH}$ coding sequence and a predicted transcriptional terminator (Fig. 1). Strains carrying the rsd1066 fusion do not have an arginine auxotrophic phenotype (data not shown).
Since $\operatorname{ArgR}$ is a known regulator of $\operatorname{argCBH}$ [12], we constructed combinatorial $\operatorname{argR}$ and $r p o S$ mutants to determine the relative contributions of each regulator to the expression of the operon. Introduction of a deletion of $\arg R$ into a strain with an $\operatorname{argCBH}$-lacZ fusion resulted in high expression with or without RpoS (Fig. 2). It is likely that RpoS-dependent expression of $\operatorname{argCBH}$ in the $\triangle \operatorname{argR}$ strains may be masked by strong derepression as a consequence of loss of ArgR.

\section{Growth phase dependence of argCBH expression}

To test if the expression of the argCBH operon is induced upon entry into stationary phase, expression of the operon was assayed in rich media. During entry into stationary phase, expression of argCBH increased 7-fold in wild type cultures, but only exhibited 3-fold increase in the $\Delta r p o S$ mutant (Table 1). This indicates that $\operatorname{argCBH}$ expression is not only growth phase-dependent but also is affected by loss of RpoS. Expression of argCBH expression was 14-fold higher in $\triangle a r g R$ mutants than in wild type strains and in these mutants, was independent of RpoS (Table 1).

\section{Effect of exogenous arginine on argCBH expression}

RpoS is likely an important factor in amino acid scavenging in stationary phase [28]. Amino acid biosynthesis offers an alternative to the scavenging strategy. It is possible that the RpoS effect on argCBH expression is more pronounced when arginine becomes limiting, as might be the case in stationary phase. To test this, expression of the operon was assessed in exponential phase cultures grown in minimal media supplemented with various concentrations of L-arginine. In strain HS1066 and its rpoS mutant derivative, HS1066p, argCBH expression was found to be inversely proportional to arginine concentration at arginine concentrations less than $60 \mu \mathrm{M}$ (Fig. 3). Arginine biosynthetic genes, including $\operatorname{argCBH}$, are normally induced in response to arginine limitation [29]. However, in exponential phase cultures, argCBH expression was RpoS dependent only at arginine concentrations below 30 $\mu \mathrm{M}$ (Fig. 3). In stationary phase, argCBH expression was 2fold RpoS-dependent at all arginine concentrations tested (data not shown).

Surprisingly, $\triangle \arg R$ mutants were impaired in growth on minimal media even when supplemented with arginine, strongly suggesting that these strains possessed an additional unidentified nutritional requirement. Intermediates in the arginine biosynthetic pathway are also precursors in other pathways. For example, carbamoylphosphate, the product of carbamoylphosphate synthetase (encoded by the bi-cistronic operon $\operatorname{car} A B$ ) is not only a precursor of arginine but is also required for pyrimidine biosynthesis [30]. Therefore, it is possible that the derepression of arginine biosynthesis may deplete car- 
Table I: Expression of the argCBH operon in rich media. Wildtype, $\triangle r p o S$ and $\triangle a r g R$ strains harboring the rsd 1066 operon lacZ-fusion to the argCBH operon were grown in LB media and assayed for $\beta$-galactosidase activity in exponential phase $\left(O D_{600}=0.3\right)$ and stationary phase $\left(O D_{600}=1.5\right)$ as described in Methods. All reported activities are the average of three independent determinations.

\begin{tabular}{llll}
\hline Strain & Genotype & & $\beta$-Galactosidase (Miller Units) \\
\cline { 3 - 3 } & & Exponential & Stationary \\
\hline HS1066 & WT & $5.6 \pm 0.34$ & $38.4 \pm 0.97$ \\
HS1066p & $\Delta r p o S$ & $6.1 \pm 0.26$ & $18.8 \pm 0.15$ \\
HS2404 & $\Delta a r g R$ & $469 \pm 18$ & $553 \pm 33$ \\
HS2405 & $\Delta r p o S \Delta a r g R$ & $486 \pm 32$ & $712 \pm 35$
\end{tabular}

bamoylphosphate required for synthesis of pyrimidine thus rendering $\triangle \arg R$ mutants auxotrophic for pyrimidine. To test this, we examined the growth of $\Delta a r g R$ mutants on minimal media supplemented with pyrimidines relative to $\arg R^{+}$strains. As shown in Table 2, the growth deficiency of $\Delta a r g R$ mutants could be completely suppressed by the addition of pyrimidines (growth of $\triangle \arg R$ and wild type strains were equivalent in the presence of added pyrimidines). We also compared the generation time of $\arg R^{+}$and $\triangle \arg R$ strains on minimal media with or without pyrimidines, and examined the average colony size by plating the cells on minimal media plates. As shown in Table 3, the generation time of $\triangle a r g R$ was much greater than that of the $\arg R^{+}$strain, and this growth impairment could be remedied by addition of pyrimidines into the media. The growth requirement was not absolute as some residual growth was observed in the $\triangle \arg R$ strain. Reduced growth could be due to either a uniform slow growth among cells or by the selection of suppressor mutants which could overcome impairment by acquiring advantageous mutations. The diameters of $\triangle \arg R$ deletion colonies were only one half that of $\arg R^{+}$ colonies indicating $\mathrm{ArgR}$ is required for robust growth in minimal media. Furthermore, the colony morphology and size of all colonies were uniform, consistent with the idea that growth results were a consequence of poor growth of $\arg R$ deletion mutants in general and were not due to suppression by selected mutants. To ensure that this was not a strain-specific phenotype, the $\Delta \arg R$ mutation was transduced and tested in another common laboratory strain, MG1655 and, as expected, the resultant transductants were similarly found to be pyrimidine limited (data not shown). To exclude the possibility that an uncharacterized mutation linked to the original operon fusion mutation was responsible for the pyrimidine phenotype, we tested an independently constructed $\arg R$ deletion mutant from the Nara KO collection [31]. This strain was similarly impaired in pyrimidine synthesis (data not shown).

We further examined the pyrimidine requirement by transforming an $\arg R$ deletion mutant with an $\arg R$-con- taining plasmid clone from the ASKA collection [31]. Colony size of the ArgR-complemented $\operatorname{argR}$ deletion mutant was more than twice that of the control strain after two days growth on minimal media $(0.76 \pm 0.03 \mathrm{~mm}$ vs. 0.34 $\pm 0.03 \mathrm{~mm})$.

\section{Effect of an astCADBE operon deletion on expression of $\operatorname{argCBH}$}

The astCADBE operon, encoding a set of enzymes responsible in the arginine succinyltransferase (AST) pathway, is RpoS-dependent and can be induced in nitrogen limited environment especially when arginine is present [11]. It is possible that RpoS affects argCBH expression through AST-mediated depletion of intracellular arginine resulting in increased derepression by ArgR. To test this possibility, an astCADBE deletion mutant was constructed in strains containing the argCBH-lacZ fusion, and the resultant mutant was assayed in rich media. In exponential phase there is not much expression difference in all these strains. However, in stationary phase, the expression of $\operatorname{argCBH}$ in $\Delta a s t$ mutation strain was nearly 2-fold (an increase of 18 units) higher than that in $\Delta r p o S \Delta a s t$ double mutation strains (Fig. 4). Thus, the RpoS-dependence of $\operatorname{argCBH}$ in $\triangle a s t$ deletion background is consistent with results obtained using $\mathrm{AST}^{+}$strains, and it is unlikely that RpoSmodulated $\operatorname{argCBH}$ expression is indirectly induced by arginine catabolism through the AST pathway. However, the expression of $\operatorname{argCBH}$ in $\triangle a s t$ mutant was slightly lower (10\% difference) than in the $\mathrm{AST}^{+}$strain, indicating that metabolism of arginine through the AST pathway may have a slight overall effect on $\operatorname{argCBH}$ expression, probably through modulation of ArgR.

\section{The effect of exogenous arginine on growth}

Since strains carrying a mutation in $\operatorname{argH}$ are auxotrophic for arginine (HS1072 this study), these strains could be used to establish the concentration at which this key amino acid becomes growth limiting. Similarly, because the operon fusion in strain HS1066 does not render the cell arginine auxotrophic but is nonetheless ArgR dependent, this strain can be used in parallel to assess ArgRdependent activation of the operon during arginine 


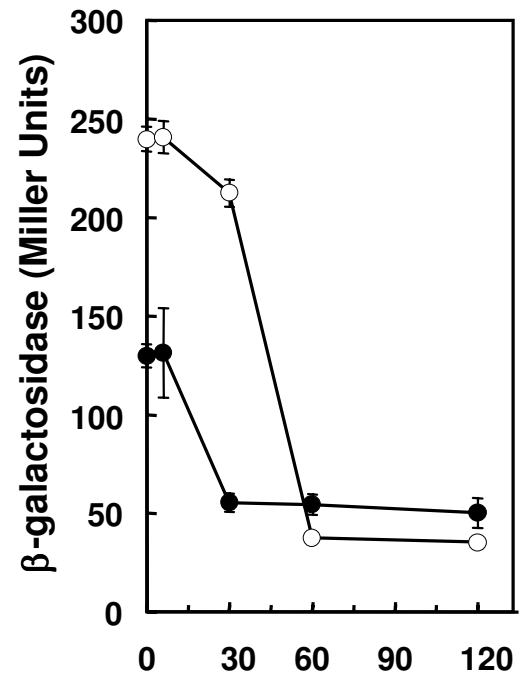

\section{Arginine Concentration $(\mu \mathrm{M})$}

\section{Figure 3}

Expression of $\operatorname{argCBH}$ in isogenic wild type $(O)$ and $r p o S$ mutant $(-)$ strains in glucose minimal media supplemented with exogenous arginine. Expression was tested in exponential phase $\left(O D_{600}=0.3\right)$

restriction. Growth of $E$. coli was impaired at arginine concentrations less than $60 \mu \mathrm{M}$ : below this level growth rate was proportional to concentration of the limiting amino acid. Growth yield was similarly affected (data not shown). Derepression of $\operatorname{argCBH}$ expression was found to occur at concentrations below $60 \mu \mathrm{M}$ and, as expected, was inversely related to arginine concentration (Fig. 5). Limitation by the availability of intracellular arginine may account for the reduced growth observed and, through ArgR derepression, may also be partially responsible for the increased expression of $\operatorname{argH}$. Together, these data indicate that $\operatorname{argCBH}$ regulation is tightly coupled to arginine availability. At $60 \mu \mathrm{M}$, even though the cultures were not arginine-limited with respect to growth, the levels of $\operatorname{argCBH}$ were five fold higher than in fully repressed cells. This suggests that, in nutrient-starved cells, argCBH derepression would occur prior to potential growth restriction by arginine limitation ensuring maximum growth yield.

\section{Northern analysis of argH expression}

Although plate expression assays indicate that $\operatorname{argH}$ expression is clearly RpoS-dependent (Fig. 2), the results of reporter gene expression studies showed that RpoS dependence was only 2-fold, somewhat less than that found for most RpoS regulated genes [26]. To resolve this discrepancy, we independently assessed expression of $\operatorname{argH}$ in wild type and $r p o S$ mutant cultures by Northern analysis (Fig. 6). Consistent with reporter gene studies on plates, expression of $\arg H$ was much higher in stationary phase cultures of the wild type strain than in the isogenic rpos mutant and was much lower in exponential phase samples of both cultures. The hybridizing argH transcript co-migrated with the $16 \mathrm{~S}$ RNA leading to some interference (Fig. 6). These results, in conjunction with the reporter fusion studies, indicate that expression of $\operatorname{argH}$ is both RpoS and stationary phase dependent in a wild type strain and is thus similar to many other RpoS-dependent genes [26].

\section{Expression of Argininosuccinate lyase, the product of argH} To determine if RpoS and ArgR modulation of $\operatorname{argH}$ expression results in changes in the level of the encoded enzyme, we assayed exponential phase cultures of strains deficient in the expression of these regulators for argininosuccinate lyase activity. This was tested by growing cultures in minimal media at suboptimal levels since the RpoS effect was most pronounced when cells were slightly starved for arginine (Fig. 3).

The specific ArgH activity in WT was about 4 fold higher than that in rpoS-strain, while it was about 25 fold higher in $\arg R^{-}$strain compared with the WT (Table 4). These results, together the lac $Z$ expression and Northern data, supports the idea modulation of $\operatorname{argH}$ expression by RpoS is reflected at the level of protein synthesis.

\section{Discussion}

In this study, we examined RpoS-dependent control of $\operatorname{argCBH}$ expression, and its modulation by ArgR and external arginine in Escherichia coli. Using independently-isolated mutants carrying operon fusions in different positions within the $\arg C B H$ region, we conducted expression studies of this biosynthetic operon by assaying reporter gene fusions and by examining $\operatorname{argH}$ transcript levels in both a wild type strain and an rpos mutant by Northern analysis. Since ArgR also regulates this operon [12], we evaluated the relative contributions of both ArgR and RpoS to its expression by constructing appropriate double and single null mutants.

RpoS regulates many genes that play important roles in stress resistance and energy metabolism [16], but a subset of these RpoS-dependent genes including gabP [26], proP [32], proU [33], gadAB [34] and $l d c C$ [35] aid in amino acid transport and utilization. In a previous genetic screen for RpoS-dependent genes [26], we identified one mutant that was auxotrophic for arginine and carried a mutation that mapped to the terminal gene member of the $\operatorname{argCBH}$ operon. To the best of our knowledge, this is the only 
Table 2: Effect of exogenous supplemented pyrimidines on growth of $\Delta$ argR strains. Overnight cultures were grown in minimal media with exogenously-supplemented L-arginine $(230 \mu \mathrm{M})$. Cultures were washed in arginine-free minimal media and replica-plated onto minimal plates supplemented with exogenous cytosine, thymine and uracil. Growth was scored after overnight incubation at $37^{\circ} \mathrm{C}$. "-" no growth on the plates after 24 hours incubation

\begin{tabular}{lllll}
\hline Strain & Genotype & & Media \\
\cline { 3 - 5 } & & LB & M9+ G & M9 + G + P \\
\hline HS1066 & WT & + & + & + \\
HS1066p & $\Delta r p o S$ & + & + & + \\
HS2404 & $\Delta$ argR & + & - & + \\
HS2405 & $\Delta r p o S \Delta a r g R$ & + & - & + \\
\hline
\end{tabular}

G, Glucose

P, Pyrimidine- Cytosine, Uracil and Thymine added at $20 \mu \mathrm{g}$ per $\mathrm{ml}$

RpoS-modulated gene known which, when mutated, renders the cell auxotrophic. As such, examining the regulation of this operon may offer unique insight into RpoScontrolled stationary phase physiology.

Our data showing that stationary phase expression of the $\operatorname{argCBH}$ operon is affected by RpoS does not reveal whether this effect is direct or indirect. In fact for many members of the RpoS regulon such information has not been established. Indirect regulation is known to be operant for at least some members, including gadA and $\operatorname{gadB}$, two glutamate decarboxylases that are among the most highly RpoS-dependent genes based on microarray analysis [27]. The expression of these genes depends on GadX, a regulator whose growth phase dependent increase expression requires RpoS [36].

RpoS can regulate its operon members directly (e.g. osm $Y$ [37]) or indirectly (e.g. gadW by the RpoS-dependent $\mathrm{GadX}$ regulator [38]). As RpoS dependence of $\operatorname{argCBH}$ was not observed in $\triangle \arg R$ mutants, $\operatorname{ArgR}$ appears to be necessary for RpoS-modulated expression of the operon. There are at least two mechanisms that could explain the increase in expression in stationary phase. In the first, as RpoS activates expression of its large regulon, depletion of intracellular arginine may result as a consequence of $d e$ novo synthesis of stationary phase proteins. This may derepress the arginine biosynthetic pathway, resulting in an increase in argCBH expression. Alternatively, increased catabolism through the RpoS-dependent AST pathway lower intracellular arginine and might also result in derepression of the operon. The latter explanation, however, seems unlikely in view of the fact that RpoS modulation of $\operatorname{argCBH}$ is not affected by deletion of the AST operon (this study).

Using the arginine auxotroph (HS1072), we found that $E$. coli becomes growth limited at arginine concentrations below $60 \mu \mathrm{M}$. As derepression also occurs at these concentrations (this study), it appears that expression of the biosynthetic pathway is closely coupled to the biosynthetic need for arginine. As the concentration of arginine in LB media is about $60 \mu \mathrm{M}[9]$, it is possible that our results could be partially explained by depletion of arginine during growth in late exponential phase. However, as supplementation with exogenous arginine did not markedly reduce stationary phase induction of the $\operatorname{argCBH}$ operon, it is likely that other mechanisms, including control by RpoS, ensure that this operon continues to be expressed under nutrient limited conditions.

Surprisingly, maximum levels of $\operatorname{argCBH}$ expression in the wild type strain were only one third of those found in an isogenic $\triangle \arg R$ mutant suggesting that $A r g R$ can be an active repressor even in the absence of exogenous arginine. This may be due to the fact that, even under starvation conditions, synthesized endogenous arginine can be an effective co-repressor. Such control may be physio-

Table 3: Effect of $\triangle a r g R$ on culture growth in minimal media. Overnight cultures in LB were washed in minimal salts 3 times and subcultured at $\mathrm{I}: 1000$ dilution into minimal media and grown at $37^{\circ} \mathrm{C}, 200 \mathrm{rpm}$, and samples were plated on minimal media to determine the average colony size.

\begin{tabular}{|c|c|c|c|c|}
\hline Strain & Genotype & Media & Generation Time (h) & Average Colony $(\mathrm{mm})$ \\
\hline HSI066 & $\arg R^{+}$ & M9 & $1.31 \pm 0.12$ & $1.21 \pm 0.02$ \\
\hline HS2404 & $\Delta \arg R$ & M9 & $2.14 \pm 0.28$ & $0.74 \pm 0.02$ \\
\hline HSI066 & $\underset{\arg R^{+}}{ }$ & $M 9+P$ & $1.21 \pm 0.07$ & $1.30 \pm 0.03$ \\
\hline HS2404 & $\Delta \arg R$ & $M 9+P$ & $1.27 \pm 0.23$ & $0.73 \pm 0.02$ \\
\hline
\end{tabular}

P, Pyrimidine- Cytosine, Uracil and Thymine added at $20 \mu \mathrm{g}$ per $\mathrm{ml}$ 


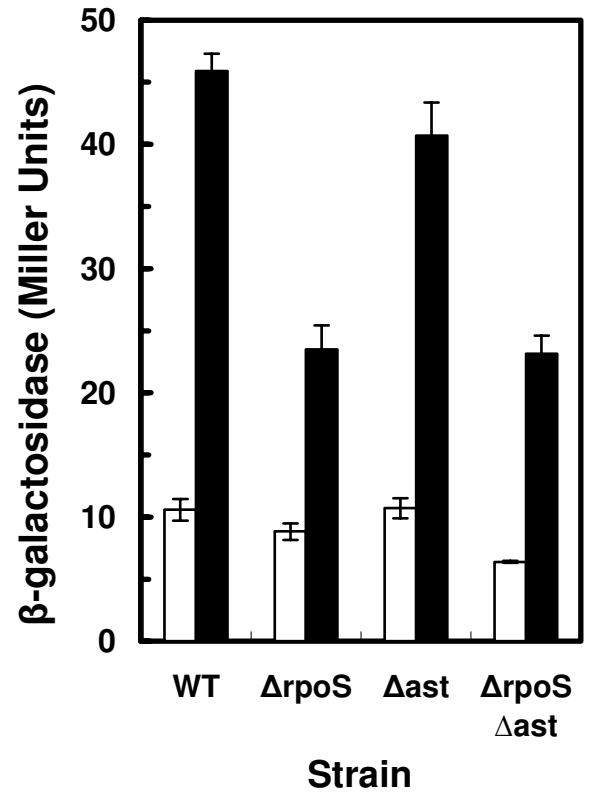

Figure 4

Effect of astCADBE depleted arginine on $\operatorname{argCBH}$ expression in wild type, $\triangle r p o S, \Delta a s t$, and $\triangle r p o S$ aast strains. Strains were grown in triplicate in LB rich media. Samples were taken in exponential phase $\left(\square, \mathrm{OD}_{600}=0.3\right)$ and stationary phase $(\mathbf{\square}$, $\mathrm{OD}_{600}=1.5$ ), and $\beta$-glactosidase activity was assayed as described in Methods.

logically necessary as carbamoylphosphate, an arginine precursor, is also required for pyrimidine biosynthesis. Balancing these two pathways, arginine and pyrimidine biosynthesis, under nutrient-limited conditions, is likely an important physiological imperative, as complete derepression of arginine biosynthesis, by deletion of $\operatorname{argR}$, causes cells to develop a partial requirement for exogenous pyrimidine (this study). The need for de novo arginine synthesis therefore appears to be balanced against other biosynthetic requirements of the cell. he multiple controls on $c a r A B$, including availability of arginine, pyrimidines as well purines [39] ensure that the synthesis of these macromolecule precursors is balanced in actively growing cells.

Why might arginine biosynthesis be stationary phase dependent? It is well established that nutrient scavenging is an important survival mechanism in starved cultures [40]. Arginine in particular is likely to be an important metabolite in stationary phase cultures for several reasons. As arginine represents 11 percent of the cells total nitrogen [11], it is potentially an important nitrogen reservoir for starving populations. Arginine is also a potential pre-

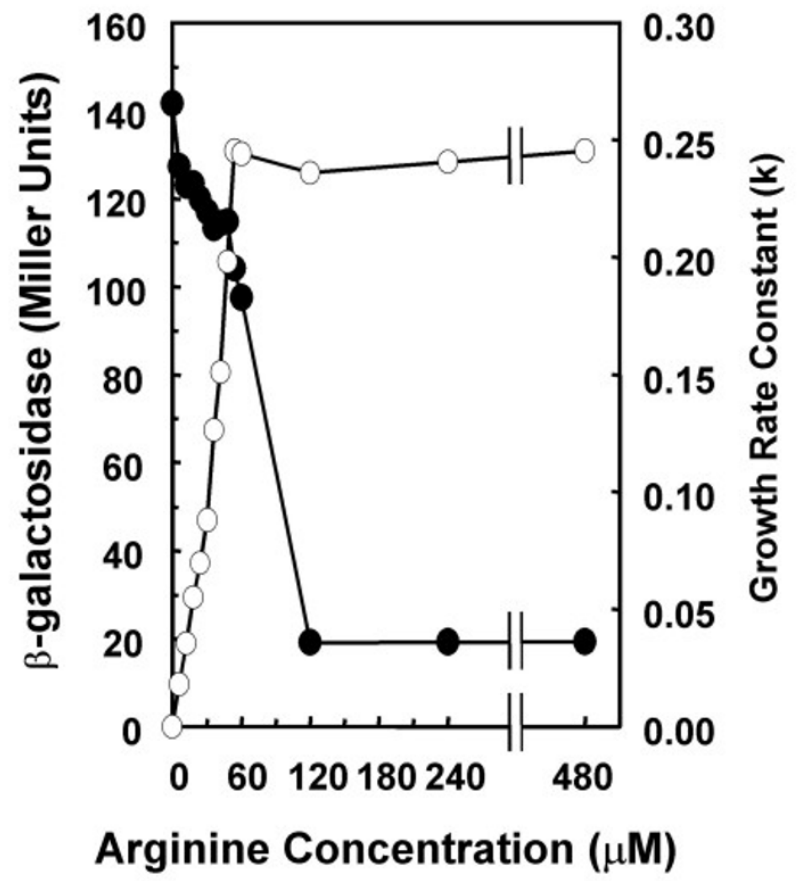

Figure 5

Effect of exogenous arginine on growth and $\arg C B H$ expression. Growth rate and $\arg C B H$ expression were determined using an arginine auxotrophic strain, HSI072 and an arginine prototrophic strain HSI066, respectively, at the indicated arginine concentrations. Overnight cultures were grown with appropriate antibiotics, sub-cultured into minimal media and maintained in exponential phase for at least 8 generations prior to the start of the experiment.

cursor for the biosynthesis of polyamines which stabilize and condense DNA during senescence [41] and protect it against oxidative damage $[7,8,42]$. Finally, as de novo protein synthesis in non-growing stationary phase cells is required for the expression of stationary phase adaptive proteins, this may impose a significant biosynthetic demand upon the cell both because there are many such proteins produced (see [16] for review) and because some of these are expressed to extraordinarily high levels. For example, Dps, a highly RpoS-dependent DNA binding protein [43], is almost undetectable in exponential phase, but accumulates to 200,000 molecules per cell in stationary phase (approx. 5\% of total cellular protein) [44]. Many genes are induced upon entry into stationary phase and it is likely that this creates a high demand for amino acids for de novo protein synthesis. The up-regulation of amino acid biosynthetic operons such as $\operatorname{argCBH}$ may provide a means to satisfy this demand in addition to nutrient scavenging mechanisms including arginine trans- 


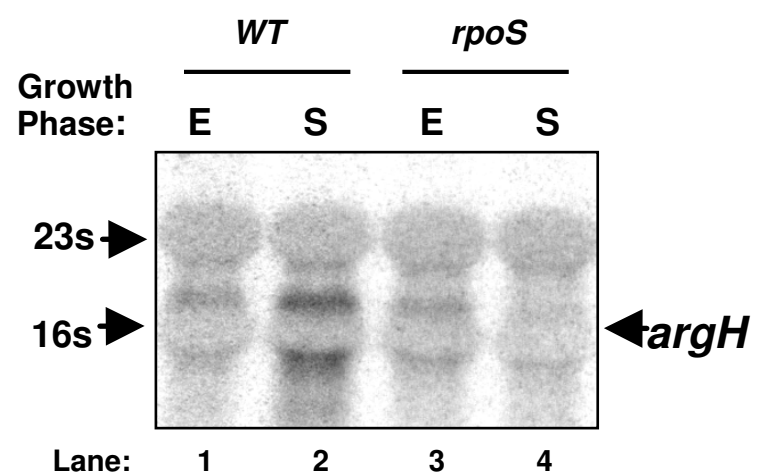

Figure 6

RpoS dependent expression of $\operatorname{argH}$ in exponential and stationary phase determined by Northern analysis. RNA was extracted from cultures grown in $L B$ to $O D_{600}=0.3$ for exponential phase $(E)$ and $O D_{600}=1.5$ for stationary phase (S) using the hot phenol method (as described in Methods). 5 $\mu \mathrm{g}$ of RNA was loaded in each lane. Signal intensity was quantified by densitometry and normalized to an arbitrary value of 10 for expression of the operon in stationary phase in the wild type strain.

port which is also a key factor in maintaining high arginine levels in stationary phase cultures [45].

Biosynthetic regulons, particularly those required for amino acid biosynthesis, are often controlled by a transcriptional repressor (e.g. TrpR and ArgR). Though $\arg \mathrm{CBH}$ operon is modulated by RpoS in stationary phase cultures the dynamic range of this control was small in relation to that exerted by ArgR. Interestingly, another member of the ArgR regulon, astC, a member of the ast$C A D B E$ operon, is RpoS-dependent to a similar degree [17]. These observations, in conjunction with the results of this study, suggest that RpoS plays an important role in coordinately regulating arginine metabolism in stationary phase. Such control is likely effective because of the nature of the pathway. ArgA-mediated synthesis of N-acetylglutamate is the first committed step in the arginine biosynthetic pathway and is controlled by 1) cumulative feedback inhibition by arginine and 2) ArgR at the level of transcription [12]. Since ArgC and ArgB catalyze early steps in this pathway and ArgH catalyzes the final biosynthetic reaction (Fig. 7), it is likely that control of these key steps by ArgR/RpoS modulates the entire arginine biosynthetic pathway.
While our studies employed a non-pathogenic E. coli K-12 strain, the results of this study may have relevance for $E$. coli pathogenesis. For example, though urine is a good growth media for uropathogenic $E$. coli [46], low concentration of several key nutrients, including arginine [46] and iron [2], can be limiting. As both transport [2] and biosynthesis [1] of arginine are required for maximum growth in urine and in minimal media containing restrictive levels of arginine, control of the functions for the metabolism of this amino acid are likely critical for urovirulence. As RpoS has now been implicated in both control of biosynthesis (this study) and catabolism of arginine [18], it will be useful, in future studies, to establish the relative importance of these metabolic functions in pathogenesis.

\section{Conclusion}

In summary, $\arg \mathrm{CBH}$ expression is clearly controlled by a finely balanced mechanism mediated by two signals: 1) a general nutrient stress signal mediated, in part, by RpoS and, 2) well known specific control through argininedependent modulation of the ArgR repressor.

\section{Methods}

\section{Bacterial strains, phage, and plasmids}

All strains used are E. coli K-12 derivatives. The bacterial strains, phage and plasmids used in this study are listed in Table 5.

\section{Media and chemicals}

All chemicals were supplied by either Sigma Chemical or Gibco BRL. Cultures were routinely grown in Luria-Bertani (LB) media and in M9 minimal media [47]. The anti-

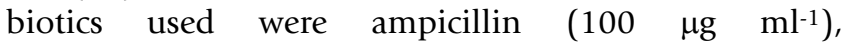
chloramphenicol $\left(25 \mu \mathrm{g} \mathrm{ml}^{-1}\right)$, kanamycin $\left(50 \mu \mathrm{g} \mathrm{ml}^{-1}\right)$, tetracycline $\left(15 \mu \mathrm{g} \mathrm{ml}^{-1}\right)$, and streptomycin $\left(100 \mu \mathrm{g} \mathrm{ml}^{-1}\right)$.

\section{Growth conditions}

All cultures were grown in triplicate from independently isolated colonies. Cell growth was monitored spectrophotometrically (Novaspec ${ }^{\circledR}$ II spectrophotometer, Pharmacia LKB Biochrom Ltd., Cambridge, England) by measuring optical density at $600 \mathrm{~nm}\left(\mathrm{OD}_{600}\right)$. Expression studies in rich media were conducted using cultures maintained in early exponential phase $\left(\mathrm{OD}_{600}\right.$ of $\left.<0.3\right)$ in antibiotic-free LB media for at least 8 generations, prior to the start of the experiment. Sub-cultures with a starting $\mathrm{OD}_{600}$ of 0.01 were grown in $\mathrm{LB}$ at $37^{\circ} \mathrm{C}$ and agitated at $200 \mathrm{rpm}$.

To quantify the RpoS dependence of argCBH expression in relation to exogenous arginine concentration in minimal media, overnight minimal media cultures $(0.4 \%$ glucose) were inoculated from well-isolated colonies on minimal media plates $(0.2 \%$ glucose $)$ and grown with appropriate antibiotics. To ensure complete repression of 
Table 4: Specific argininosuccinate lyase (ASL) activity in exponential culture of WT, rpos-, and $\triangle a r g R$ strains. Cultures were grown in $M 9$ minimal media supplemented with $30 \mu \mathrm{M} L$-arginine and harvested at $O D_{600 \mathrm{~nm}}=0.3$. Cell extracts were assayed as described in the Methods section. ASL enzyme assay values were corrected for the low background levels of non-specific activity in the argH- mutant.

\begin{tabular}{llcc}
\hline Strain & Genotype & $\begin{array}{c}\text { Argininosuccinate lyase (U/ } \\
\text { mg protein) }\end{array}$ & Per cent of wild type \\
\hline GC4468 & WT & $6.50 \pm 0.083$ & 100 \\
GCI22 & rpoS- & $1.53 \pm 0.86$ & 24 \\
HS2404 & argR & $159.6 \pm 22.0$ & 2,455 \\
HSI072 & argH-lacZ & 0 & 0 \\
\hline
\end{tabular}

arginine biosynthesis, the overnight cultures were supplemented with $230 \mu \mathrm{M}$ L-arginine. The cultures were diluted (1 in 1000) and maintained in early exponential phase (as described above) prior to the start of experiments in antibiotic-free minimal media supplemented with $230 \mu \mathrm{M} \mathrm{L-}$ arginine. At an $\mathrm{OD}_{600}$ of 0.3 , cultures were placed on ice for $2 \mathrm{~min}$ and then centrifuged for $10 \mathrm{~min}$ at $4000 \times \mathrm{g}$ at room temperature. The supernatant was decanted and the resulting cell pellets washed twice with arginine-free minimal media to remove remaining exogenous arginine. The arginine-free cell pellets were re-suspended in minimal media to the same optical density as collected. A series of sub-cultures with a starting $\mathrm{OD}_{600}$ of 0.05 were made into minimal media supplemented with various concentrations of exogenous L-arginine. The sub-cultures were incubated at $37^{\circ} \mathrm{C}$ and agitated at $200 \mathrm{rpm}$. For each concentration of L-arginine, samples were taken in midexponential phase $\left(\mathrm{OD}_{600}\right.$ of 0.3 ) and assayed for $\beta$-galactosidase activity

\section{Enzyme Assays}

$\beta$-galactosidase activity was assayed as previously described by Miller [47]. ONPG was used as the substrate, and activity was expressed in Miller units [47]. All cultures were grown in triplicate from independent colony isolates (biological replicates) and all assays were performed in duplicate.

Argininosuccinate lyase (ASL) activity was determined by measuring the absorbance of fumarate hydrolyzed from argininosuccinate at $\mathrm{OD}_{240 \mathrm{~nm}}$ [48]. Cell extracts were prepared by sonication [49]. The reaction mixtures containing $10 \mathrm{ug} / \mathrm{ml}$ protein, $1.0 \mathrm{mM}$ argininosuccinate in 50 $\mathrm{mM}$ potassium phosphate buffer ( $\mathrm{pH} 7.5)$ were monitored photometrically at $\mathrm{OD}_{240 \mathrm{~nm}}$. One unit of ASL activity corresponds to 1 nmole L-argininosuccinate hydrolysized per min at $\mathrm{pH} 7.5$ and $37^{\circ} \mathrm{C}$.

Construction of $\triangle \mathrm{argR}$ and $\triangle \mathrm{astCADBE}$ deletion mutants The one-step chromosomal gene inactivation procedure of Datsenko and Wanner [50] was used to generate precise $\triangle a r g R$ and $\triangle a s t C A D B E$ deletion mutations. The mutation was transduced [47] into other strains using P1vir transduction (see Table 5).

The pKD3 plasmid was used as a template to amplify the PCR fragments used for replacement of the $\arg R$ and ast$C A D B E$ target genes. Primers were designed such that the resulting PCR product includes the $\mathrm{Cm}^{\mathrm{r}}$ cassette from

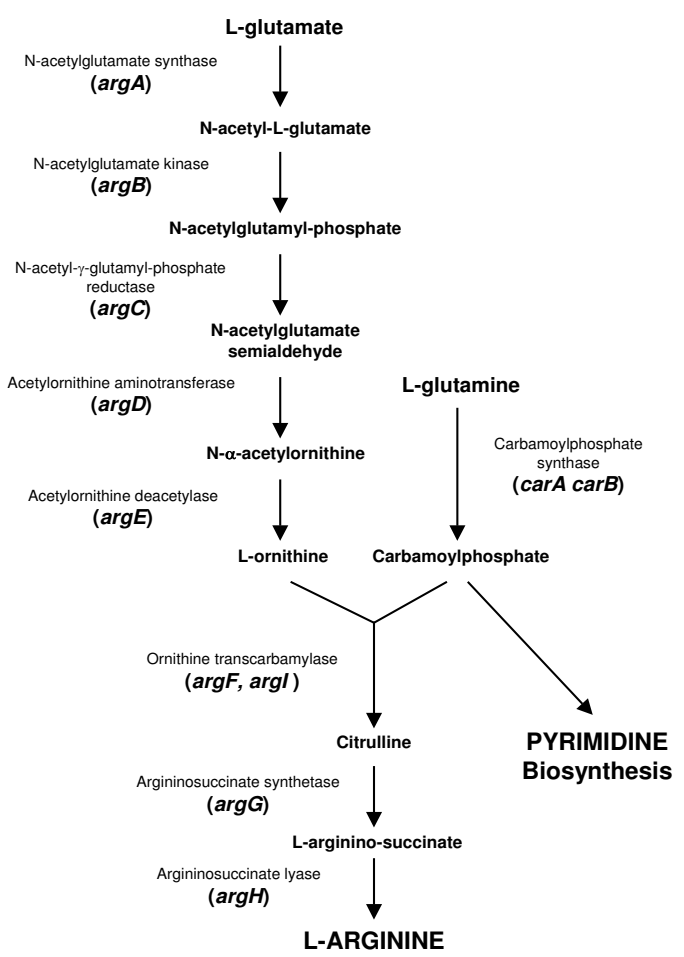

\section{Figure 7}

The arginine biosynthetic pathway. Note that ArgF and Argl are ornithine transcarbamylase, while the carAB operon encodes subunits of carbamoylphosphate synthase. Adapted from EcoCyc: Encyclopedia of Escherichia coli Genes and Metabolism http://biocyc.org/ecocycl. 
Table 5: E. coli strains and bacteriophage used in this study.

\begin{tabular}{|c|c|c|}
\hline Strains & Genotype & Source/Reference \\
\hline MGI655 & Prototrophic E. coli K-12, $\mathrm{F}^{-} \lambda-r p h$ & CGSC, Yale University \\
\hline GC4468 & $\Delta$ lacUI69 rpsL & \\
\hline $\mathrm{GCl} 22$ & as GC4468 but rpos $13:: \operatorname{Tn} 10$ & [49] \\
\hline HSI066 & $\begin{array}{l}\text { as GC } 4468 \text { but } \arg H^{+}-\lambda \text { placMu53 }[\Phi(\operatorname{argH}- \\
\text { lacZ)66](rsd } 066)\end{array}$ & [26] \\
\hline HSI066p & as HSI066 but rpoSI $3:: \operatorname{Tn} 10$ & [26] \\
\hline HSI072 & $\begin{array}{l}\text { as GC } 4468 \text { but } \arg H^{-}-\lambda \text { placMu53[ } \Phi(\arg H- \\
\text { lacZ)72](rsd } 1072)\end{array}$ & [26] \\
\hline HSI072p & as HSI072 but rpoSI $3:: \operatorname{Tn} 10$ & [26] \\
\hline HS240I & as MGI 655 but $\triangle \operatorname{argR}::$ cat & This study \\
\hline HS2402 & as GC 4468 but $\Delta a r g R::$ cat & $\mathrm{PI}(\mathrm{HS} 240 \mathrm{I}) \times \mathrm{GC} 4468 \rightarrow \mathrm{Cm}^{\mathrm{R}}$ \\
\hline HS2403 & as $\mathrm{GCI} 22$ but $\triangle \operatorname{argR}::$ cat & $\mathrm{PI}(\mathrm{HS} 240 \mathrm{I}) \times \mathrm{GCl} 22 \rightarrow \mathrm{Cm}^{\mathrm{R}}$ \\
\hline HS2404 & as HSI 066 but $\triangle a r g R: .: c a t$ & $\mathrm{PI}(\mathrm{HS} 240 \mathrm{I}) \times \mathrm{HSI} 066 \rightarrow \mathrm{Cm}^{\mathrm{R}}$ \\
\hline HS2405 & as HSI066p but $\triangle$ argR::"cat & $\mathrm{PI}(\mathrm{HS} 240 \mathrm{I}) \times \mathrm{HSI} 066 \mathrm{p} \rightarrow \mathrm{Cm}^{\mathrm{R}}$ \\
\hline HS2406 & as $\mathrm{HSI} 072$ but $\triangle a r g R:$. cat & $\mathrm{PI}(\mathrm{HS} 240 \mathrm{I}) \times \mathrm{HSI} 072 \rightarrow \mathrm{Cm}^{\mathrm{R}}$ \\
\hline HS2407 & as HSI 072 p but $\triangle a r g R:: c a t$ & $\mathrm{PI}(\mathrm{HS} 240 \mathrm{I}) \times \mathrm{HSI} 072 \mathrm{p} \rightarrow \mathrm{Cm}^{\mathrm{R}}$ \\
\hline HS3006 & As $\mathrm{HSI} 066$ but $\triangle a s t C A D B E:: c a t$ & This study \\
\hline HS3006p & As HS3006 but rpoS/3::Tn 10 & $\mathrm{PI}(\mathrm{HS} 3006) \times \mathrm{HSI} 066 \mathrm{p} \rightarrow \mathrm{Cm}^{\mathrm{R}}$ \\
\hline \multicolumn{3}{|l|}{ B) Phage } \\
\hline PIvir & generalized transducing phage & Laboratory stock \\
\hline \multicolumn{3}{|c|}{ C) Plasmids } \\
\hline pKD3 & $\begin{array}{l}\text { Template plasmid for gene disruption, cat is } \\
\text { flanked by FRT sites. }\end{array}$ & {$[50]$} \\
\hline pKD46 & $\begin{array}{l}\lambda \text { Red recombinase expression plasmid under } \\
\text { control of an araC- } P_{\text {araB }} \text { inducible promoter. }\end{array}$ & {$[50]$} \\
\hline $\mathrm{pArgR}$ & Derivative of $\mathrm{pCA} 24 \mathrm{~N}$ & H. Mori [3I] \\
\hline
\end{tabular}

pKD3 flanked by sequences adjacent to the target reading frame in the MG1655 chromosome. The PCR primers used for $\operatorname{argR}$ were: forward 5'-CAATAATGTTG TATCAACCACCATATCGGGTGACTTGTGTAGGCTGAAGCTGCTTC-3' and reverse 5'ACATTTTCCCCGCCGTCAGAAACGACGGGGCAGAGACATATGA ATATCCTCCTTAG-3'; primers used for creating astCADBE deletion were: forward 5'-ACTTAATACCCGCAGAATGATTTCTGCGGGTAAGTAGTGTAGG CTGGAGCTGCTTC-3' and reverse 5'CATATAAATAACGAATTATTTACTGTA GAGGTCGCTCATATGAATATCCTCCTTAG-3'. The bold text corresponds to target gene flanking sequences, and normal text represents DNA sequences of the $\mathrm{Cm}^{\mathrm{r}}$ cassette. The deletion generated the entire target coding sequence.

Incorporation of the $\mathrm{Cm}^{\mathrm{r}}$ cassette into the MG1655 chromosome was confirmed by PCR using genomic DNA as a template and confirmational primers. The confirmational forward primers used were the forward primers (as described above). The reverse confirmational primer for $\operatorname{argR}$ was 5'-TGTCGCA GTAAAACGCACTA-3', for astCADBE was 5'-TTATACGCAAGGCGACAAGG-3'.

All primers were synthesized by MOBIXLab, McMaster University (Hamilton, ON).

\section{RNA Isolation and Northern Analyses}

RNA was isolated from cultures grown in LB using the hot phenol method [51]. Primers to the $\operatorname{argH}$ gene (5'-CGGTTCAAACAATTCAACGA-3' and 5'-GCAGCTTTTTGCCTAACTGG-3') were used to PCR-amplify a DNA probe for hybridization studies to examine stationary phase and RpoS dependence of $\operatorname{argH}$ expression. RNA samples were prepared, separated by electrophoresis and hybridized as previously described [26]. Probes were prepared and radioactively labeled by PCR as described in [52]. Densitometric analysis of the bands was performed using a Storm ${ }^{\circledast}$ (Amersham Biosciences, Inc., Baie d'Urfe, QC) gel and blotting imaging system with ImageQuant ${ }^{\mathrm{TM}}$ v 5.2 (Amersham Biosciences, Inc.).

\section{Authors' contributions}

J.P.W. and T.D performed most of the experiments and, with M.R.S., wrote the first draft. M.R.S. also performed the Northern analysis. M.G.K. aided in the construction of the $\arg R$ deletion strains and helped in the design of several experiments. S.Y. designed and conducted additional arginine supplementation experiments. H.E.S was the principal investigator and supervised the project.

\section{Acknowledgements}

This work was supported by grants from the Natural Sciences and Engineering Research Council (NSERC) of Canada to H.E. Schellhorn. We thank C.M. Patten, Y.D. Li and S. Tariq for critical review of the manuscript. 
We also thank E. Brown for supplying strains from the Nara collection and $\mathrm{H}$. Mori and co-workers for developing these collections and making them available for general use. M.R. Schertzberg was supported by an Ontario Graduate Scholarship and M.G. Kirchhof was the recipient of an NSERC undergraduate summer scholarship.

\section{References}

I. Russo TA, Jodush ST, Brown J], Johnson JR: Identification of two previously unrecognized genes (guaA and argC) important for uropathogenesis. Mol Microbiol 1996, 22:217-229.

2. Russo TA, Carlino UB, Mong A, Jodush ST: Identification of genes in an extraintestinal isolate of Escherichia coli with increased expression after exposure to human urine. Infect Immun 1999, 67:5306-53|4

3. Castanie-Cornet MP, Penfound TA, Smith D, Elliott JF, Foster JW: Control of acid resistance in Escherichia coli. J Bacteriol 1999 | 8 I:3525-3535.

4. Lin J, Smith MP, Chapin KC, Baik HS, Bennett GN, Foster JW: Mechanisms of acid resistance in enterohemorrhagic Escherichia coli. Appl Environ Microbiol 1996, 62:3094-3100.

5. Price SB, Cheng CM, Kaspar CW, Wright JC, DeGraves FJ, Penfound TA, Castanie-Cornet MP, Foster JW: Role of rpoS in acid resistance and fecal shedding of Escherichia coli O157:H7. Appl Environ Microbiol 2000, 66:632-637.

6. McFall E, Newman EB: Amino Acids as Carbon Sources. In Escherichia coli and Salmonella: cellular and molecular biology Volume 22. 2nd edition. Edited by: Neidhardt FC. Washington, DC, ASM Press; 1996:360-360.

7. Khan AU, Di Mascio P, Medeiros MH, Wilson T: Spermine and spermidine protection of plasmid DNA against single-strand breaks induced by singlet oxygen. Proc Natl Acad Sci U S A 1992 89: I |428-I | 430.

8. Khan $\mathrm{AU}$, Mei $\mathrm{YH}$, Wilson $\mathrm{T}$ : A proposed function for spermine and spermidine: protection of replicating DNA against damage by singlet oxygen. Proc Natl Acad Sci U S A 1992 , 89: | |426-1|427.

9. Cui S, Meng J, Bhagwat AA: Availability of glutamate and arginine during acid challenge determines cell densitydependent survival phenotype of Escherichia coli strains. Appl Environ Microbiol 2001, 67:49|4-4918.

10. Gerard F, Dri AM, Moreau PL: Role of Escherichia coli RpoS, LexA and $\mathrm{H}-\mathrm{NS}$ global regulators in metabolism and survival under aerobic, phosphate-starvation conditions. Microbiology 1999, I 45 ( Pt 7): 1547-I562.

II. Kiupakis AK, Reitzer L: ArgR-independent induction and ArgRdependent superinduction of the astCADBE operon in Escherichia coli. I Bacteriol 2002, I 84:2940-2950.

12. Maas WK: The arginine repressor of Escherichia coli. Microbiol Rev 1994, 58:631-640.

13. Smith MC, Czaplewski L, North AK, Baumberg S, Stockley PG: Sequences required for regulation of arginine biosynthesis promoters are conserved between Bacillus subtilis and Escherichia coli. Mol Microbiol 1989, 3:23-28.

14. Tian G, Lim D, Carey J, Maas WK: Binding of the arginine repressor of Escherichia coli KI 2 to its operator sites. J Mol Biol 1992 226:387-397.

15. Chang DE, Smalley DJ, Conway T: Gene expression profiling of Escherichia coli growth transitions: an expanded stringent response model. Mol Microbiol 2002, 45:289-306.

16. Ishihama A: Functional modulation of Escherichia coli RNA polymerase. Annu Rev Microbiol 2000, 54:499-5I 8.

17. Baca-DeLancey RR, South MM, Ding X, Rather PN: Escherichia coli genes regulated by cell-to-cell signaling. Proc Natl Acad Sci U S A 1999, 96:4610-4614.

18. Fraley CD, Kim JH, McCann MP, Matin A: The Escherichia coli starvation gene cstC is involved in amino acid catabolism. J Bacteriol 1998, I 80:4287-4290.

19. Hengge-Aronis R: Back to log phase: sigma $\mathbf{S}$ as a global regulator in the osmotic control of gene expression in Escherichia coli. Mol Microbiol 1996, 2 I:887-893.

20. Loewen PC, Hengge-Aronis R: The role of the sigma factor sigma S (KatF) in bacterial global regulation. Annu Rev Microbiol 1994, 48:53-80.

21. Kowarz L, Coynault C, Robbe-Saule V, Norel F: The Salmonella typhimuriumkatF (rpoS) gene: cloning, nucleotide sequence, and regulation of spvR and SpvABCD virulence plasmid genes. J Bacteriol 1994, I 76:6852-6860.

22. Levinthal M, Pownder T: hns, rpoS and Irp mutations affect stationary-phase survival at high osmolarity. Res Microbiol 1996, I 47:333-342.

23. Culham DE, Lu A, Jishage M, Krogfelt KA, Ishihama A, Wood JM: The osmotic stress response and virulence in pyelonephritis isolates of Escherichia coli: contributions of RpoS, ProP, ProU and other systems. Microbiology 200I, I 47:I657-I670.

24. Krogfelt KA, Hjulgaard M, Sorensen K, Cohen PS, Givskov M: rpoS gene function is a disadvantage for Escherichia coli BJ4 during competitive colonization of the mouse large intestine. Infect Immun 2000, 68:25 I 8-2524.

25. Robey M, Benito A, Hutson RH, Pascual C, Park SF, Mackey BM: Variation in resistance to high hydrostatic pressure and rpoS heterogeneity in natural isolates of Escherichia coli O 1 57:H7. Appl Environ Microbiol 200I, 67:490I-4907.

26. Schellhorn HE, Audia JP, Wei LI, Chang L: Identification of conserved, RpoS-dependent stationary-phase genes of Escherichia coli. I Bacteriol 1998, 180:6283-6291.

27. Vijayakumar SR, Kirchhof MG, Patten CL, Schellhorn HE: RpoS-regulated genes of Escherichia coli identified by random lacZ fusion mutagenesis. I Bacteriol 2004, I 86:8499-8507.

28. Zinser ER, Kolter R: Mutations enhancing amino acid catabolism confer a growth advantage in stationary phase. J Bacterio | 999, | 8 |:5800-5807.

29. Williams MG, Rogers P: Expression of arg genes of Escherichia coli during arginine limitation dependent upon stringent control of translation. J Bacteriol 1987, I 69: 1644-1650.

30. Glansdorff N: Biosynthesis of Arginine and Polyamines. In Escherchia coli and Salmonella: cellular and molecular biology 2nd edition. Edited by: Neidhardt FC. Washington, DC, ASM Press; 1996:408-433.

3I. Arita M, Robert M, Tomita M: All systems go: launching cell simulation fueled by integrated experimental biology data. Curr Opin Biotechnol 2005, 1 6:344-349.

32. Mellies J, Wise A, Villarejo M: Two different Escherichia coli proP promoters respond to osmotic and growth phase signals. J Bacteriol 1995, I77:|44-I5I.

33. Manna D, Gowrishankar J: Evidence for involvement of proteins $H U$ and RpoS in transcription of the osmoresponsive proU operon in Escherichia coli. J Bacteriol 1994, I 76:5378-5384.

34. De Biase D, Tramonti A, Bossa F, Visca P: The response to stationary-phase stress conditions in Escherichia coli: role and regulation of the glutamic acid decarboxylase system. Mol Microbiol 1999, 32:1198-1211.

35. Kikuchi $Y$, Kurahashi O, Nagano T, Kamio Y: RpoS-dependent expression of the second lysine decarboxylase gene in Escherichia coli. Biosci Biotechnol Biochem 1998, 62:1267-1270.

36. Ma Z, Richard H, Tucker DL, Conway T, Foster JW: Collaborative regulation of Escherichia coli glutamate-dependent acid resistance by two AraC-like regulators, GadX and GadW (YhiW). J Bacteriol 2002, I 84:700I-70I2.

37. Hengge-Aronis R, Lange R, Henneberg N, Fischer D: Osmotic regulation of rpoS-dependent genes in Escherichia coli. J Bacteriol 1993, I 75:259-265.

38. Ma Z, Richard H, Foster JW: pH-Dependent modulation of cyclic AMP levels and GadW-dependent repression of RpoS affect synthesis of the $\mathbf{G a d X}$ regulator and Escherichia coli acid resistance. J Bacteriol 2003, 185:6852-6859.

39. Devroede N, Thia-Toong TL, Gigot D, Maes D, Charlier D: Purine and pyrimidine-specific repression of the Escherichia coli carAB operon are functionally and structurally coupled. $J \mathrm{Mol}$ Biol 2004, 336:25-42.

40. Ferenci T: Adaptation to life at micromolar nutrient levels: the regulation of Escherichia coli glucose transport by endoinduction and CAMP. FEMS Microbiol Rev 1996, I8:301-317.

4I. Davis RH, Morris DR, Coffino P: Sequestered end products and enzyme regulation: the case of ornithine decarboxylase. Microbiol Rev 1992, 56:280-290.

42. Ha HC, Sirisoma NS, Kuppusamy P, Zweier JL, Woster PM, Casero RAJ: The natural polyamine spermine functions directly as a free radical scavenger. Proc Natl Acad Sci U S A 1998, 95: I I 40 - I I 45 .

43. Altuvia S, Almiron M, Huisman G, Kolter R, Storz G: The dps promoter is activated by OxyR during growth and by IHF and sigma S in stationary phase. Mol Microbiol 1994, 13:265-272. 
44. Martinez A, Kolter R: Protection of DNA during oxidative stress by the nonspecific DNA-binding protein Dps. J Bacteriol 1997, 179:5188-5194.

45. Lacour S, Landini P: SigmaS-dependent gene expression at the onset of stationary phase in Escherichia coli: function of sigmaS-dependent genes and identification of their promoter sequences. J Bacteriol 2004, 186:7|86-7/95.

46. Hull RA, Hull SI: Nutritional requirements for growth of uropathogenic Escherichia coli in human urine. Infect Immun 1997, 65:1960-1961.

47. Miller JH: A short course in bacterial genetics. Cold Spring Harbor,, Cold Spring Harbor Press; 1992.

48. Ratner S: Argininosuccinase. Methods Enzymol 1970, I71:304-309.

49. Schellhorn HE, Stones VL: Regulation of katF and katE in Escherichia coli K-I 2 by weak acids. J Bacteriol 1992, 1 74:4769-4776.

50. Datsenko KA, Wanner BL: One-step inactivation of chromosomal genes in Escherichia coli K-12 using PCR products. Proc Natl Acad Sci U S A 2000, 97:6640-6645.

5I. Kohrer K, Domdey H: Preparation of high molecular weight RNA. Methods Enzymol 1991, 194:398-405.

52. Sambrook J, Russell DW: Molecular cloning:a labaratory manual. Cold Spring Harbor,, Cold Spring Harbor Press; 200I.

Publish with Bio Med Central and every scientist can read your work free of charge

"BioMed Central will be the most significant development for disseminating the results of biomedical research in our lifetime. "

Sir Paul Nurse, Cancer Research UK

Your research papers will be:

- available free of charge to the entire biomedical community

- peer reviewed and published immediately upon acceptance

- cited in PubMed and archived on PubMed Central

- yours - you keep the copyright

Submit your manuscript here:

http://www.biomedcentral.com/info/publishing_adv.asp
BioMedcentral 